Revised version, submitted to Comparative Biochemistry and Physiology Part C Special BLM Issue, April 2002

\title{
Comparison of measured and modelled copper binding by natural organic matter in freshwaters
}

${ }^{a}$ Centre for Ecology and Hydrology (Windermere Laboratory), Ambleside, Cumbria LA22

OLP, United Kingdom. ${ }^{\mathrm{b}}$ Institute of Environmental and Biological Sciences, University of

* Present address: Westlakes Research Institute, The International Post Graduate Centre, Westlakes Science and Technology Park, Moor Row, Cumbria CA24 $3 J Y$

Correspondence to: Dr Edward Tipping

Centre for Ecology and Hydrology (Windermere Laboratory)

Ambleside

Cumbria

LA22 0LP

United Kingdom

Phone $\quad+44(0) 1539442468$

Fax $\quad$ +44 (0) 1539446914

e-mail_et@ceh.ac.uk 


\section{Abstract}

Fifteen freshwater samples containing significant concentrations of dissolved organic carbon - [DOC] - were titrated with copper under standardised conditions (pH 6 and 7), and concentrations of $\mathrm{Cu}^{2+}-\left[\mathrm{Cu}^{2+}\right]-$ were measured with an ion-selective electrode. Measured values of $\left[\mathrm{Cu}^{2+}\right]$, which were in the range $10^{-11}$ to $10^{-5} \mathrm{~mol} \mathrm{~L}$, were compared with those simulated using Humic Ion-Binding Models V and VI. It was assumed that copper speciation was controlled by the organic matter, represented by fulvic acid (FA), together with inorganic solution complexation (calculated with an inorganic speciation model). The models were calibrated by adjusting a single quantity, the concentration of FA. The optimised value $[\mathrm{FA}]_{\mathrm{opt}}$ - was that giving the best agreement, according to least squares, between measured and simulated $\left[\mathrm{Cu}^{2+}\right]$. The calculations took into account competition by other dissolved (filterable) metals ( $\mathrm{Mg}, \mathrm{Al}, \mathrm{Ca}, \mathrm{Fe}(\mathrm{II}), \mathrm{Fe}(\mathrm{III}), \mathrm{Zn}$ ); in the case of $\mathrm{Fe}(\mathrm{III})$ it was assumed either that all the dissolved metal was truly in solution, or that the activity of $\mathrm{Fe}^{3+}$ was controlled by equilibrium with $\mathrm{Fe}(\mathrm{OH})_{3}$. The assumption about $\mathrm{Fe}(\mathrm{III})$ had relatively small effects on the fitting of Model V, but was significant for Model VI, because Model VI represents lowabundance, high-affinity binding sites in humic matter, which are sensitive to $\mathrm{Fe}(\mathrm{III})$ competition. Because of its inclusion of the high-affinity sites, Model VI provided better fits of the data than did Model V. Furthermore, Model VI with $\mathrm{Fe}^{3+}$ activity controlled by $\mathrm{Fe}(\mathrm{OH})_{3}$ gave smaller variation in the ratio of $[\mathrm{FA}]_{\mathrm{opt}}$ to [DOC] than Model VI with all $\mathrm{Fe}(\mathrm{III})$ assumed to be in solution. The average $[\mathrm{FA}]_{\mathrm{opt}} /[\mathrm{DOC}]$ found from the $\mathrm{Cu}$ titrations was 1.30 , which implies that $65 \%$ of the organic matter is "active" with respect to metal binding. The average ratio of 1.30 is in reasonable agreement with ratios obtained by applying the model to field data sets for charge balance (1.22), Al speciation (1.56) and base titrations of $\mathrm{Cu}$ amended waters (1.45). It is concluded that Model VI / $\mathrm{Fe}(\mathrm{OH})_{3}$ provides the most reliable predictions of dissolved metal speciation in natural waters; at a total $\mathrm{Cu}$ concentration of 1 $\mu \mathrm{M}$, the predicted concentration of $\mathrm{Cu}^{2+}$ is expected to be correct to within a factor of 3.6 in $95 \%$ of cases.

Keywords: dissolved organic carbon; copper; speciation; model; freshwater 


\section{Introduction}

The Biotic Ligand Model (BLM; Paquin et al., 2000) combines a chemical equilibrium model that describes metal speciation (including the biotic ligand) with a toxicity model that relates accumulation of metal at the biotic ligand to toxic effect. The toxicological parts of the model have been developed and tested using the results of laboratory experiments (e.g. Playle et al., 1993; MacRae et al., 1999; Meyer et al., 1999). Its application to field situations will rely on the chemical equilibrium sub-model to account for the interactions of potentially toxic metals with other solutes, and perhaps eventually particulate matter. It is clearly desirable to determine how well the chemical equilibrium sub-model can describe the metal chemistry of natural waters. The purpose of the work described here was to test the abilities of the current solution speciation model used in the BLM (Humic Ion-Binding Model V; Tipping and Hurley, 1992), and of a recent improved version (Model VI; Tipping, 1998), to simulate copper speciation in freshwater samples.

The present study builds upon previous work in which humic ion-binding models have been tested with data on charge balance and aluminium speciation (Tipping et al., 1991) and on copper speciation in $\mathrm{Cu}$-amended natural waters titrated with base (Dwane and Tipping, 1998). It was found that in order to account for observed speciation in field samples, a calibration procedure has to be performed, involving the "binding activity" of natural organic matter. For waters, satisfactory results have been achieved by assuming the cation-binding agent to have the properties of isolated fulvic acid (FA). Comparison of the concentrations of FA that give the best agreement between observation and model prediction showed that between 40 and $80 \%$ of the dissolved organic carbon has to be due to FA, the rest being assumed inert with respect to ion binding.

These previous model-testing studies have involved proton and metal binding at the most abundant, lowest affinity, binding sites of natural organic matter. Potentially toxic metals such as $\mathrm{Ni}, \mathrm{Cu}, \mathrm{Zn}, \mathrm{Cd}$ and $\mathrm{Pb}$ will generally be present at relatively low concentrations, even in polluted waters, and so less abundant, higher affinity, sites will be important. The existence and influence of the high affinity sites in humic substances have come to prominence in the research agenda, following the experimental and modelling work of Benedetti et al. (1995) and Kinniburgh et al. (1996, 1999), which demonstrated the high degree of heterogeneity in binding site strengths in isolated humic acids. To describe metal binding by isolated humic matter at low site occupancies, Model V was modified, its 
successor (Model VI; Tipping, 1998) providing a better description of the heterogeneity of humic binding sites.

In the present work we tested the abilities of Models V and VI to account for the speciation of $\mathrm{Cu}$ added to natural water samples containing varying amounts of dissolved natural organic matter. We sampled and analysed a total of fifteen samples, and performed $\mathrm{Cu}$ titrations under standardised conditions, determining $\left[\mathrm{Cu}^{2+}\right]$ using an ion-selective electrode. The observed values of $\left[\mathrm{Cu}^{2+}\right]$ were compared with simulated values, generated by Models V and VI.

In the following text, square brackets - [ ] - indicate concentrations, $a_{\mathrm{X}}$ the solution activity of species X, DOC dissolved organic carbon, FA fulvic acid, HA humic acid and $I$ ionic strength.

\section{Humic Ion-Binding Models V and VI}

15

Detailed descriptions have been given of Model V (Tipping and Hurley, 1992) and Model VI (Tipping, 1998). The models use a structured formulation of discrete, chemically plausible, binding sites for protons, to allow the creation of regular arrays of bidentate (and tridentate in Model VI) binding sites for metals. Electrostatic interactions, dependent upon net humic charge, ionic strength and the charge of the combining cation, are dealt with using a one-parameter $(P)$ empirical expression. A Donnan sub-model is used to account for counterion accumulation; each counterion can be assigned a selectivity coefficient $\left(K_{\text {sel }}\right)$. Fulvic and humic acids are assumed to be rigid spheres of uniform size, with ion-binding groups positioned randomly on the molecular surfaces. Proton dissociation is represented by postulating eight groups with different acid strengths. The dissociation reaction can be written generally as

$$
(\mathrm{HumH})^{\mathrm{Z}}=(\mathrm{Hum})^{\mathrm{Z}-1}+\mathrm{H}^{+}
$$

where Hum represents the humic molecule, and $Z$ is the net charge. The reactions are characterised by intrinsic equilibrium constants, the negative logarithms of which are denoted by $\mathrm{p} K_{1}-\mathrm{p} K_{8}$. The four most strongly-acid groups (groups $1-4$ ) are referred to as type $\mathrm{A}$ groups, and consist mainly of carboxylic acid groups, while the remaining four groups (type B) represent weaker acids, such as phenolic acids. The eight $\mathrm{p} K_{i}$ values are expressed in terms of four constants $\left(\mathrm{p} K_{\mathrm{A}}, \mathrm{p} K_{\mathrm{B}}, \Delta \mathrm{p} K_{\mathrm{A}}\right.$ and $\left.\Delta \mathrm{p} K_{\mathrm{B}}\right)$ as follows 


$$
\begin{array}{ll}
\text { for } i=1-4 & \mathrm{p} K_{i}=\mathrm{p} K_{\mathrm{A}}+\frac{(2 i-5)}{6} \Delta \mathrm{p} K_{\mathrm{A}} \\
\text { for } i=5-8 & \mathrm{p} K_{i}=\mathrm{p} K_{\mathrm{B}}+\frac{(2 i-13)}{6} \Delta \mathrm{p} K_{\mathrm{B}}
\end{array}
$$

Thus the values of $\mathrm{p} K_{\mathrm{A}}$ and $\mathrm{p} K_{\mathrm{B}}$ are the average $\mathrm{p} K$ values of the two types of group, while $\Delta \mathrm{p} K_{\mathrm{A}}$ and $\Delta \mathrm{p} K_{\mathrm{B}}$ are measures of the spread of the individual $\mathrm{p} K_{i}$ values around the means. Positive values of $\Delta \mathrm{p} K_{\mathrm{A}}$ and $\Delta \mathrm{p} K_{\mathrm{B}}$ mean that the $\mathrm{p} K_{i}$ values increase as $i$ increases, i.e. the groups become progressively weaker acids. Each type A group is assigned an abundance of $n_{\mathrm{A}} / 4 \mathrm{~mol} \mathrm{~g}^{-1}$ humic matter, and each type B group an abundance of $n_{\mathrm{A}} / 8 \mathrm{~mol} \mathrm{~g}{ }^{-1}$. Thus, within a type, each group is present in equal amounts, and there are half as many type B groups as type A groups. The imposed regularity of the groups facilitates the formulation of multidentate binding sites for metals.

Metal ions (apart from $\mathrm{Na}^{+}, \mathrm{K}^{+}$and other monovalent cations that bind very weakly), and their first hydrolysis products, compete with each other, and with protons, for the type A and type B groups. Monodentate binding at type A sites is formulated as metal-proton exchanges, characterised by the constant $K_{\mathrm{MHA}}$, and an analogous constant $\left(K_{\mathrm{MHB}}\right)$ applies to the type B sites. The strength of binding of metal ions to the four type A sites parallels the strength of proton-binding to those sites. Again, the expressions are analogous for the type B sites. When fitting data with the model, the values of $K_{\mathrm{MHA}}$ and $K_{\mathrm{MHB}}$ are the optimised quantities for each metal ion.

Bidentate sites are generated by combining pairs of proton-binding sites, and can be AA or A-B sites. The equilibrium constants are the products of the values for the individual sites. The pairing of proton-binding sites to form bidentate sites is arranged so that all sites are equally represented, and all bidentate sites are present in equal abundance, but only 12 of the possible 36 combinations are used to avoid unnecessary computation. Only proton-dissociating sites that are sufficiently close together are able to form bidentate sites. Proximities are estimated statistically by assuming the sites to be on the surface of the sphere (Tipping and Hurley, 1992). Pairs of groups form bidentate sites if they are less than or equal to $0.45 \mathrm{~nm}$ apart. Sites that are close enough to pair up take part only in bidentate reactions with metal cations, i.e. they cannot form monodentate complexes. The fraction of proton-dissociating sites able to form pairs is denoted by $f_{p r}$.

The maximum number of parameter values that can be optimised is six for proton dissociation $\left(n_{\mathrm{A}}, \mathrm{p} K_{\mathrm{A}}, \mathrm{p} K_{\mathrm{B}}, \Delta \mathrm{p} K_{\mathrm{A}}, \Delta \mathrm{p} K_{\mathrm{B}}, \mathrm{P}\right)$ and three $\left(K_{\mathrm{MHA}}, K_{\mathrm{MHB}}, K_{\text {sel }}\right)$ for each metal cation. Three parameters (radius, molecular weight and proximity factor) are fixed from the start, from 
literature information and a priori assumptions. In practice it has been found that reasonable results can be obtained by establishing a relationship between the two parameters for metalbinding, $K_{\mathrm{MHA}}$ and $K_{\mathrm{MHB}}$, and for dilute systems such as freshwaters all values of $K_{\text {sel }}$ can usually be set to unity.

Model VI was developed from Model V firstly to obtain a wider range of binding affinities for metal ions, and secondly to relax the parallel relationship between metal and proton-binding. With regard to proton-dissociating groups, the assumed molecular dimensions, and the electrostatic sub-model, Models V and VI are identical. They differ only in the way in which metal-binding reactions are formulated. Instead of using metal-proton exchanges, equilibrium constants for the binding of metal ions at deprotonated sites are employed. Monodentate binding takes place according to the general reaction

$$
\operatorname{Hum}^{Z}+\mathbf{M}^{z}=(\mathrm{HumM})^{Z+z}
$$

The equilibrium constants are given by

$$
\begin{array}{ll}
\text { for sites 1-4: } & \log K(i)=\log K_{\mathrm{MA}}+\frac{(2 i-5)}{6} \Delta L K_{\mathrm{A} 1} \\
\text { for sites 5-8: } & \log K(i)=\log K_{\mathrm{MB}}+\frac{(2 i-13)}{6} \Delta L K_{\mathrm{B} 1}
\end{array}
$$

where $\Delta L K_{\mathrm{A} 1}$ and $\Delta L K_{\mathrm{B} 1}$ are constants. Thus the values of $\log K_{\mathrm{MA}, i}$ are evenly spaced around the mean of $\log K_{\mathrm{MA}}$ but the spacing is not necessarily the same as that for protons, which is the case in Model $\mathrm{V}$, i.e. in general $\Delta L K_{1}$ is not equal to $-\Delta \mathrm{p} K_{\mathrm{A}}$. The same applies to the type $\mathrm{B}$ sites.

In Model VI, metal cations and their first hydrolysis products may bind at both bidentate and tridentate sites. For a bidentate site comprising single sites $j$ and $k$, the association constant $K(j, k)$ is given by

$$
\log K(j, k)=\log K(j)+\log K(k)+x \Delta L K_{2}
$$

where $\Delta L K_{2}$ is an adjustable parameter. The value of $x$ is zero for $90.1 \%$ of the sites, 1 for 9 $\%$, and 2 for $0.9 \%$. This generates heterogeneity, with a small number of strong sites, a larger number of moderately strong ones, and a majority of weak ones. Analogous rules are used for the tridentate sites, made up of single sites $l, m$ and $n$

$$
\log K(l, m, n)=\log K(l)+\log K(m)+\log K(n)+y \Delta L K_{2}
$$

Here, $y$ is $0,1.5$ or 3 for the $90.1 \%, 9 \%$ and $0.9 \%$ abundances. Each metal ion has a characteristic $\Delta L K_{2}$. 
The fractions of single sites that contribute to the bidentate or tridentate sites are determined statistically, as in Model V, by assuming the proton sites to be randomly positioned on the surfaces of the (spherical) molecules. The fraction of sites forming bidentate sites is denoted by $f_{p r B}$, that for tridentates is $f_{p r T}$. For fulvic acid, $f_{p r B}=0.42, f_{p r T}=0.03$, while for humic acid, the corresponding values are 0.50 and 0.065. In Model VI, if all combinations of proton sites are allowed, 36 different bidentate sites and 120 different tridentate sites can form, for each of which there are three binding strengths, if $\Delta L K_{2}$ is non-zero. Together with the eight monodenate sites, there could be 476 different sites in all. The site abundances depend on their composition, in terms of type A and type B sites, the latter being present at half the total abundance of the former. For example, tridentate sites comprising three type A proton sites are eight times more abundant than those comprising three type B sites. To avoid overcomplication, and to speed computations, a sub-set of sites is used in the model, while maintaining the relative proportions of the contributing proton sites. Bidentate or tridentate sites are allowed to consist only of different proton sites, and only 24 representative combinations are adopted. The 24 allowed combinations lead to 72 different sites, because of the heterogeneity terms (equations 7 and 8). With the addition of the eight monodentate sites, there are 80 different sites in all.

In Model VI, the maximum number of parameters that can be optimised to describe proton dissociation is six, exactly as in Model V. For each metal cation (plus its first hydrolysis product), up to six could be optimised ( $\left.K_{\mathrm{MA}}, K_{\mathrm{MB}}, \Delta L K_{\mathrm{A} 1}, \Delta L K_{\mathrm{B} 1}, \Delta L K_{2}, K_{\mathrm{sel}}\right)$, although the number can be reduced substantially by taking into account data for many metals.

Values of model parameters used in this study are given in Tables 1 and 2. For application to natural water samples, the humic binding models were combined with an inorganic speciation model, the database for which was presented by Tipping (1994). The combination of Model V with the inorganic speciation model is the core of the Windermere Humic Aqueous Model (WHAM; Tipping, 1994).

\section{Methods}

\subsection{Sample collection and analysis for major solutes}

At each site, a $15 \mathrm{~L}$ sample of water was collected in $5 \mathrm{~L}$ acid washed polyethylene containers taking care not to disturb any sediment. Powder-less gloves were worn throughout 
the sampling procedure, and containers were rinsed with some sample water prior to collection. Samples were transported to the lab as soon as possible after collection, and were filtered (Whatman, GF/F) before storage in the dark at $4^{\circ} \mathrm{C}$. A sub sample was acidified after filtering for trace metal analysis. The $\mathrm{pH}$ of the sample was determined using a Radiometer combination electrode (GK2401C) at the temperature of the natural water. The sample was collected in a glass stoppered bottle taking care not to entrain any air. The electrode was calibrated using BDH buffers at $\mathrm{pH} 7$ and 4 . The quality of the electrode was tested using a $10^{-4} \mathrm{M} \mathrm{HCl}$ solution prepared by accurate dilution of a $0.1 \mathrm{M}$ certified standard (Fisons) (Davison, 1990). Dissolved organic carbon was determined on the filtered sample using a Dohrmann DC190 high temperature TOC analyser. A Perkin-Elmer 2380 atomic absorption spectrophotometer was used to analyse the filtered samples for major cations $\left(\mathrm{Na}^{+}, \mathrm{Mg}^{2+}, \mathrm{K}^{+}\right.$, $\left.\mathrm{Ca}^{2+}\right)$. A Dionex 2000i/SP was used to analyse for major anions $\left(\mathrm{Cl}^{-}, \mathrm{NO}_{3}{ }^{-}, \mathrm{SO}_{4}{ }^{2-}\right)$ by high performance ion chromatography (HPIC). A PQe/Eclipse inductively coupled mass spectrometer (ICP-MS) was used to determine trace metal concentrations ( $\mathrm{Al}, \mathrm{Mn}, \mathrm{Cu}, \mathrm{Zn}$, $15 \mathrm{Cd}, \mathrm{Pb})$, on samples acidified $\left(1 \% \mathrm{HNO}_{3}\right)$ immediately after filtration. Alkalinity was determined by Gran titration. Ferrous iron in filtered samples was determined spectrophotometrically using bathophenanthroline without the addition of a reductant, total iron was measured following overnight reduction with hydroxylammonium chloride, and ferric iron was obtained by difference.

\subsection{Copper titrations}

The same titration protocol was applied to each natural water sample, thereby allowing direct comparisons to be made amongst samples. To ensure that significant binding by dissolved organic matter would take place, titrations were performed at $\mathrm{pH} 6$ and $\mathrm{pH} 7$. The effect of ionic strength was examined by carrying out the $\mathrm{pH} 6$ titrations on one sample with no added salt and on another with the ionic strength increased to $\sim 0.1 \mathrm{M}$.

Amounts of acid or base required to achieve the desired $\mathrm{pH}$ values were determined as follows. One hundred $\mathrm{cm}^{3}$ of the filtered water sample was placed in a $200 \mathrm{~cm}^{3}$ tall form beaker, held within a thermostatic jacket at $20^{\circ} \mathrm{C}$. The solution was stirred at a constant rate using a magnetic stirrer, while being bubbled with water-saturated air, enriched to $10^{-3}$ atm with $\mathrm{CO}_{2}$ to improve $\mathrm{pH}$ buffering. The $\mathrm{pH}$ was monitored with a Radiometer combination electrode (GK2401C) calibrated using pH 7 and 4 buffers (BDH). Solution pH values were adjusted by adding measured volumes of $0.01 \mathrm{M} \mathrm{HNO}_{3}$ or $\mathrm{NaOH}$. The $\mathrm{pH}$ was considered 
stable once it had remained the same $( \pm 0.02 \mathrm{pH})$ for one hour; this could take up to 8 hours for high-alkalinity samples. Starting solutions for copper titrations were prepared by adding the volume of acid or base needed to adjust the $\mathrm{pH}$ to the required value ( $\mathrm{pH} 6$ or 7 ) to a 1 litre volumetric flask, together with $25 \mathrm{~cm}^{3}$ of $4 \mathrm{M} \mathrm{NaNO}_{3}$ (AnalaR, BDH) if a high ionic strength solution was required. The flask was made to volume accurately, using the filtered natural water sample, with vigorous shaking. Approximately 800 grams of the solution was then weighed accurately to two decimal places into a 1 litre tall form beaker. The beaker was placed in a thermostatic jacket at $20^{\circ} \mathrm{C}$ and was covered with a loose fitting lid. The solution was stirred at a constant rate using a magnetic stirrer and was bubbled with water-saturated air, enriched with $\mathrm{CO}_{2}\left(\mathrm{pCO}_{2}=0.001 \mathrm{~atm}\right)$ in order to improve $\mathrm{pH}$ buffering.

The $\mathrm{Cu}$ ion selective electrode (ISE) was prepared according to the manufacturer's instructions, and was calibrated in terms of activities using $\mathrm{Cu}\left(\mathrm{NO}_{3}\right)_{2}$ solutions in the range $10^{-6}-10^{-3} \mathrm{M}$. The ionic strength of the calibration standard solutions was adjusted to $0.005 \mathrm{M}$ for the low ionic strength titrations and $0.1 \mathrm{M}$ for titrations at $I=0.1 \mathrm{M}$. The calibration potentials were taken once the $\mathrm{mV}$ reading had remained constant $\pm 0.1 \mathrm{mV}$ for 3 minutes. A Nernstian response was invariably achieved. The calibrated $\mathrm{Cu}$ ISE and a $\mathrm{pH}$ combination electrode were introduced to the titration solution through holes in the loose fitting lid, and the system was covered with a black bag to prevent light interfering with the $\mathrm{Cu}$ ISE. The electrodes were allowed to soak in the solution for 20 minutes and the $\mathrm{pH}$ was checked. Any fine adjustments to the $\mathrm{pH}$ were made using dilute acid $\left(0.1 \mathrm{M} \mathrm{HNO}_{3}\right)$ or base $(0.1 \mathrm{M} \mathrm{NaOH})$ noting the volumes added. Additions of titrant $\left(\mathrm{Cu}\left(\mathrm{NO}_{3}\right)_{2}\right)$ were made with a carefully calibrated automatic pipette, and total $[\mathrm{Cu}]$ in the system was calculated by combining the added $\mathrm{Cu}$ with the $\mathrm{Cu}$ of the original water sample $(\leq 0.06 \mu \mathrm{M})$. At low total $[\mathrm{Cu}]$, the potential given by the ISE fell slightly in response to additions of $\mathrm{Cu}$, then passed through a threshold concentration, above which the expected positive response was observed. Only data points for total $[\mathrm{Cu}]$ clearly above the threshold were accepted. Depending mainly on [DOC], the threshold concentration was in the range $0.1-1 \mu \mathrm{M}$. Measured potentials were accepted when the drift was $<0.1 \mathrm{mV}$ in 3 minutes. This took up to 1 hour for the initial input, and approximately 20 minutes for readings thereafter. The $\mathrm{pH}$ electrode potential was recorded at the same time as the $\mathrm{Cu}$ ISE potential. The $\mathrm{pH}$ changed relatively little $(<0.2$ units $)$ during a titration; model calculations were performed using the measured $\mathrm{pH}$ value as input. The total $\mathrm{Cu}$ concentration at the end of the titration was $10-20 \mu \mathrm{M}$. Once the final potential had been recorded the electrodes were removed from the solution, rinsed and their calibrations checked. 
Each titration was carried out in duplicate, so that six titrations were carried out for each sample. The average number of data points per sample was 39 (range 18-53).

\section{Results}

\subsection{Water compositions}

Surface water samples were collected from 15 sites (lakes, ponds, streams and rivers) in northern England and the south west of Scotland (Table 3). Water chemistries ranged from softwater and acid to hardwater and alkaline. They were predominantly unpolluted, but some (Rivers Aire and Calder, River Tees at Neasham and Stockton) received industrial and sewage effluents, while others (Rivers Ouse and Derwent) were influenced by agricultural runoff and point-source sewage inputs. The Rivers Ouse and Derwent are less polluted, and receive predominantly agricultural runoff and point source sewage effluent. There is little variation in the [DOC] for all of these rivers. The differences in pollution may result in differences in physical and chemical properties of DOC (Tipping et al., 1997). Further details about the rivers and their organic matter contents are given by Jarvie et al. (1997) and Tipping et al. (1997).

\subsection{Cu titration results}

The $\mathrm{Cu}$ ISE permitted values of $\left[\mathrm{Cu}^{2+}\right]$ as low as $10^{-11} \mathrm{M}$ to be detected in experiments on samples with high [DOC] at $\mathrm{pH} 7$. In contrast, the lowest concentration for samples with relatively low $[\mathrm{DOC}]$ - and therefore poorer buffering of $\left[\mathrm{Cu}^{2+}\right]-$ at $\mathrm{pH} 6, \mathrm{I}=0.1 \mathrm{M}$ was typically $10^{-7} \mathrm{M}$. In all cases, substantial amounts of $\mathrm{Cu}$ were complexed, the more so at low total copper concentrations. For example, the data points in Fig. 1 for $[\mathrm{Cu}]_{\text {total }}<10^{-6}$ show c. $98 \%$ complexation at $\mathrm{pH} 6, I=0.1 \mathrm{M}, 99 \%$ at $\mathrm{pH} 6$, natural $I$, and $99.8 \%$ at $\mathrm{pH} 7$, natural $I$. Little binding by inorganic ligands $\left(\mathrm{OH}^{-}, \mathrm{HCO}_{3}{ }^{-}, \mathrm{CO}_{3}{ }^{2-}\right)$ is expected, which means that organic matter is the main complexing agent. The lowest amounts of $\mathrm{Cu}$ bound in our experiments corresponded to loadings of c. $5 \times 10^{-6} \mathrm{~mol}$ (g organic matter) ${ }^{-1}$, the highest to c. $5 \times 10^{-4} \mathrm{~mol}$ (g organic matter) ${ }^{-1}$. This is a comparatively wide range, greater than reported for many experiments with isolated humic substances, and not much less than that obtained for comparable $\mathrm{pH}$ values by Benedetti et al. (1995) in their work with high concentrations of 
HA, which demonstrated the high degree of heterogeneity in binding-site strength for $\mathrm{Cu}$. The sequence of binding always followed the pattern of Fig. 1, increasing in the order

$$
\{\mathrm{pH} 6, I=0.1 \mathrm{M}\}<\{\mathrm{pH} \text {, natural } I\}<\{\mathrm{pH} 7 \text {, natural } I\}
$$

The increase in binding with $\mathrm{pH}$ is due to decreasing competition by $\mathrm{H}^{+}$, while the lower

binding at high ionic strength reflects the smaller electrostatic attraction between the metal cation and the negatively-charged humic molecules.

\subsection{Model applications}

In optimising the models, it was assumed that the only proton and metal-binding agents in the filtered natural water samples were humic substances, represented by FA, and inorganic solutes. The default model parameters of Tables 1 and 2 were fixed. Inputs to the model, at each titration point, were total concentrations of $\mathrm{Cu}$, major solutes (Table 3), adjusted for dilution and any additions, $\mathrm{pH}, \mathrm{pCO}_{2}$, and total concentrations of $\mathrm{Fe}(\mathrm{II})$ and $\mathrm{Zn}$ (not shown in Table 3). Thus, the model calculated $\mathrm{Cu}$ speciation, taking into account competition among metals and protons for binding sites on FA, and among inorganic ligands. Concentrations of FA - $[\mathrm{FA}]_{\mathrm{opt}}$ - were found that gave the best least-squares agreement between observed and simulated concentrations of $\mathrm{Cu}^{2+}$ in the titrations. More elaborate schemes could have been tried, for example by including both FA and HA in the analysis, or by adjusting one or more of the model parameters. However, we consider that the simple approach, based on the commonest form of humic matter in natural waters (i.e. FA), is the most appropriate, given the current state of knowledge. Thus, to calibrate the model for a given sample, only a single quantity - $[\mathrm{FA}]_{\mathrm{opt}}$ - was adjusted. The inputs to the calculations comprised the measured solute concentrations at each titration step. In the case of $\mathrm{Fe}$ (III) the physicochemical form of the metal was uncertain, since it could have been present in true solution (i.e. as monomeric metal) and/or as colloidal iron hydroxide. Therefore two assumptions were made, first that all the $\mathrm{Fe}(\mathrm{III})$ was present as a monomeric solute, and second that the activity of $\mathrm{Fe}^{3+}$ was controlled by equilibrium with $\mathrm{Fe}(\mathrm{OH})_{3}$. The solubility product of $\mathrm{Fe}(\mathrm{OH})_{3}\left(\mathrm{a}_{\mathrm{Fe} 3+} / \mathrm{a}_{\mathrm{H}+}{ }^{3}\right)$ was taken to be $10^{2.5}$ at $25^{\circ} \mathrm{C}$ (Baes and Mesmer, 1976). For each titration, both models were applied, with both assumptions about Fe(III), making four optimisations in all. To interpret the results, ratios of $[\mathrm{FA}]_{\mathrm{opt}}$ to [DOC] were computed. The ratio would be close to 2.0 if all DOC were due to FA, assuming the FA to be $50 \%$ carbon.

Table 4 summarises the results obtained. In terms of root-mean-squared-deviations, Model VI performed better than Model V in 12 of the 15 samples. Another noteworthy feature of the results is that the variability of $[\mathrm{FA}]_{\mathrm{opt}} /[\mathrm{DOC}]$ is smallest for Model VI with 
precipitated $\mathrm{Fe}(\mathrm{OH})_{3}$, as is evident from comparison of the standard deviations in Table 4. Fig. 1 provides an illustration of the trends in goodness-of-fit. The main effect of assuming solubility control by $\mathrm{Fe}(\mathrm{OH})_{3}$ is the diminution of the amount of $\mathrm{Fe}(\mathrm{III})$ taking part in the binding reactions; this is why the $[\mathrm{FA}]_{\mathrm{opt}} /[\mathrm{DOC}]$ ratios are lower when $\mathrm{Fe}(\mathrm{OH})_{3}$ is assumed to be present. In fact, the results are rather insensitive to the choice of solubility product for $\mathrm{Fe}(\mathrm{OH})_{3}$, as long as it is lower than $10^{4.0}$. We conclude that the best description of the $\mathrm{Cu}$ titration data obtained in the present work comes from Model VI with precipitated $\mathrm{Fe}(\mathrm{OH})_{3}$. Fig. 2 shows four examples of the application of this version of Model VI.

Comparisons can be made with results obtained by applying the models to other data sets. As shown in Table 5, the average $[\mathrm{FA}]_{\text {opt }} /[\mathrm{DOC}]$ ratios obtained with Model VI are less varied than those with Model V. This can be explained by the greater range of binding-site heterogeneity provided by Model VI. The two models perform similarly for relatively high degrees of site saturation, but Model V needs a greater $[\mathrm{FA}]_{\mathrm{opt}}$ to account for the present data set, because low site occupancies of $\mathrm{Cu}$ have been achieved. Model VI accounts for the four datasets using quite similar $[\mathrm{FA}]_{\mathrm{opt}} /[\mathrm{DOC}]$ ratios.

\subsection{Complexation of $\mathrm{Cu}$ by carbonate species}

The calculations performed in the present work employed the inorganic data base supplied with the standard WHAM software (Tipping, 1994). This data base includes a value for the formation constant of $\mathrm{CuHCO}_{3}{ }^{+}$which may be too high. The $\log \mathrm{K}$ value used, based on an estimate by Mattigod and Sposito (1979), is 14.62 (for the reaction $\mathrm{Cu}^{2+}+\mathrm{H}^{+}+\mathrm{CO}_{3}{ }^{2-}=$ $\mathrm{CuHCO}_{3}{ }^{+}$), whereas the equivalent recommended value in the NIST data base (Smith et al., 1995) is only 12.13. Therefore the present calculations may have overestimated the importance of $\mathrm{CuHCO}_{3}{ }^{+}$. Table 6 illustrates the effect on the calculated value of $\left[\mathrm{Cu}^{2+}\right]$, which is the key species in the application of the BLM. The results calculated with the two equilibrium constants differ most for $\mathrm{pH} 7$ with zero or low concentrations of DOC; at higher [DOC], complexation by the organic matter controls $\left[\mathrm{Cu}^{2+}\right]$. In the absence of DOC, there are only small differences in $\left[\mathrm{Cu}^{2+}\right]$ at $\mathrm{pH} 5.5$, where there is little complexation of the metal by carbonate species, and also at $\mathrm{pH}$ 8.5, where complexation by carbonate species is considerable, but where the complex $\mathrm{CuCO}_{3}$, rather than $\mathrm{CuHCO}_{3}{ }^{+}$, is dominant.

Uncertainty about the formation constant of $\mathrm{CuHCO}_{3}{ }^{+}$will have had little effect on the estimation of Model V or Model VI binding parameters, because the great majority of experimental data sets with isolated humic matter were obtained under conditions where $\mathrm{Cu}$ complexation by carbonate species was negligible. Therefore, it is safe to continue to use the 
model parameters obtained by averaging values derived from individual data sets (e.g. Tipping and Hurley, 1992; Tipping, 1994, 1998). With regard to the calibration of the model as described in the present work, the use of the lower formation constant for $\mathrm{CuHCO}_{3}{ }^{+}$leads to small changes in values of $[\mathrm{FA}]_{\mathrm{opt}}$. Thus, calibration of Model VI, assuming precipitation of $\mathrm{Fe}(\mathrm{OH})_{3}$ and the lower value of the formation constant, yields an overall conversion factor of 1.36 , only slightly greater than the value of 1.30 obtained with the higher formation constant (cf. Table 4).

\section{Discussion}

Models V and VI have been parameterised almost entirely with laboratory data from studies of the binding of single metals by isolated humic substances. Their application to the chemistry of an individual metal in field samples relies not only on the parameter values for that metal, but also on the values for competing metals, and of course protons. Given this interdependence of parameters, i.e. the need for a coherent parameter set, it is difficult to justify the adjustment of individual values in order to fit field data, unless detailed measurements are made of the binding of all the relevant metals at a range of $\mathrm{pH}$ values. Even if this could be done, the issue of the "binding activity" of natural organic matter would still need to be resolved. In the present work, we attributed all differences between measured and simulated values of $\left[\mathrm{Cu}^{2+}\right]$ to variations in "binding activity" among the water samples. This led to ranges of $[\mathrm{FA}]_{\mathrm{opt}} /[\mathrm{DOC}]$ ratios, the smallest range $(0.80-1.82)$ being found for Model VI with $\mathrm{Fe}(\mathrm{OH})_{3}$ precipitation. Since that model format also provided the lowest average error between observed and simulated $\left[\mathrm{Cu}^{2+}\right]$ (Table 4), it is the preferred means to estimate $\mathrm{Cu}$ speciation in field samples. The average $[\mathrm{FA}]_{\mathrm{opt}} /[\mathrm{DOC}]$ ratio of 1.30 (or 1.36 if the lower stability constant for $\mathrm{CuHCO}_{3}{ }^{+}$is used; Section 4.4) implies that $65 \%$ (68\%) of the DOC is due to organic matter that possesses the cation binding properties of average isolated FA, while the remainder of the DOC is inert with respect to ion binding. This value agrees well with estimates from other field measurements (Table 5). It could arise because of a genuine split between active and inactive DOC, or could reflect a continuum of molecules with varying binding properties. Another possibility is that, during isolation, additional binding sites are generated in humic matter, leading to greater ion-binding activity in laboratory studies. Finally, the optimisation of [FA] may be compensating for inaccuracies in the fixed binding parameters. The finding that only part of the organic matter is required to explain the experimental measurements makes it unlikely that other significant binding agents 
(e.g. mineral colloids or anthropogenic organic ligands) have been overlooked, for the samples and ranges of total copper concentration studied. It can be noted that, at lower total copper concentrations, a significant part of the metal may be present in strong complexes with non-humic ligands, for example sulphur-containing species (Rozan et al., 2000).

Routine calculations of copper speciation are best made using the mean $[\mathrm{FA}]_{\mathrm{opt}} /[\mathrm{DOC}]$ ratios given in Table 4. To illustrate the application of this procedure, we calculated $\left[\mathrm{Cu}^{2+}\right]$ for all the titration points in the present study with $[\mathrm{Cu}]_{\text {tot }}=1 \mu \mathrm{M}$, and compared them with the measured values. The plots in Fig. 3 show that Model V predicts $\left[\mathrm{Cu}^{2+}\right]$ to within $0.8 \log$ units (a factor of 6.3) in 95\% of cases, while Model VI is somewhat more precise, predicting to within a factor of 3.6 in $95 \%$ of cases. If it is accepted that the samples studied in the present work are representative of natural freshwaters, then these errors can be assigned to estimates of $\left[\mathrm{Cu}^{2+}\right]$ made for any freshwater to which the models are applied.

In conclusion, the results show the models to provide realistic predictions of copper speciation in mildly-perturbed field samples. With plausible assumptions about the nature of natural organic matter, the models are able to account for the dependence of binding on total metal concentration, competition by protons and other metals, and the effects of ionic strength. With regard to solution-phase chemical speciation, we can therefore have confidence in the field applicability of the Biotic Ligand Model.

\section{Regulatory implications}

Studies of the kind reported here are necessary to test the speciation modelling aspects of BLM applications. Regulators can use the findings to judge whether such modelling is sufficiently convincing to be employed practically. Furthermore, we have provided indications of uncertainty in the modelling outputs, which Regulators can use to decide upon appropriate safety factors in setting acceptable copper concentrations.

\section{Acknowledgements}

We are grateful to the staff of the CEH Windermere Chemical Analytical Laboratory for help with water analysis, and to the Freshwater Biological Association for a grant to S.E.B. 


\section{References}

Baes, C.F., Mesmer R.E., 1976. Hydrolysis of Cations. Wiley, New York.

Benedetti, M.F., Milne, C.J., Kinniburgh D.G., van Riemsdijk, W.H., Koopal, L.K., 1995. Metal-ion binding to humic substances - application of the nonideal competitive adsorption model. Environ. Sci. Technol. 29, 446-457.

Davison, W., 1990. A practical guide to $\mathrm{pH}$ measurement in freshwaters. Trends Anal. Chem. $9,80-83$.

Dwane, G.C., Tipping, E., 1998. Testing a humic speciation model by titration of copperamended natural waters. Environ. Int. 24, 609-616.

Hollis, L., Muench, L., Playle, R.C., 1997. Influence of dissolved organic matter on copper binding, and calcium on cadmium binding, by gills of rainbow trout. J. Fish Biol. 50, 703-720.

Jarvie, H.P., Neal, C., Leach, D.V., Ryland, G.P., House, W.A., Robson, A.J., 1997. Major ion concentrations and the inorganic carbon chemistry of the Humber rivers. Sci. Tot. Env. 194/195, 285-302.

Kinniburgh D.G., Milne C.J., Benedetti M.F., Pinheiro J.P., Filius J., Koopal L., van Riemsdijk W.H., 1996. Metal ion binding by humic acid: application of the NICA-Donnan model. Environ. Sci. Technol. 30, 1687-1698.

Kinniburgh, D.G., van Riemsdijk, W.H., Koopal, L.K., Borkovec, M., Benedetti, M.F., Avena, M.J., 1999. Ion binding to natural organic matter: competition, heterogeneity, stoichiometry and thermodynamic consistency. Coll. Surf. A 151, 147-166.

MacRae, R.K., Smith, D.E., Swoboda-Colberg, N., Meyer, J.S., Bergman, H.L., Di Toro, D.M., 1999. Copper binding affinity of rainbow trout (Orcorhynchus mykiss) and brook trout (Salvelinus fontinalis) gills. Environ. Toxicol. Chem. 18, 1180-1189.

Mattigod, S.V., Sposito, G., 1979. Chemical modelling of trace metal equilibria in contaminated soil solutions using the computer program GEOCHEM. In Chemical Modeling in Aqueous Systems (Edited by Jenne, E.A.), pp. 837-856. Am. Chem. Soc., Washington, D.C.

Meyer, J.S., Santore, R.C., Bobbitt, J.P., Debrey, L.D., Boese, C.J., Paquin, P.R., Allen, H.E., Bergman, H.L., DiToro, D.M., 1999. Binding of nickel and copper to fish gills predicts toxicity when water hardness varies, but free-ion activity does not. Environ. Sci. Technol. 33, 913-916. 
Paquin, P.R., Santore, R.C., Wu, K.B., Kavvadas, C.D., Di Toro, D.M., 2000. The biotic ligand model: a model of the acute toxicity of metals to aquatic life. Environ. Sci. Pol. 3, S175-S182.

Playle, R.C., Dixon, D.G., Burnison, K., 1993. Copper and cadmium binding to fish gills: estimates of metal-gill stability constants and modelling of metal accumulation. Can. J. Fish. Aquat. Sci. 50, 2678-2687.

Rozan, T.F., Lassman, M.E., Ridge, D.P. \& Luther III, G.W. (2000) Evidence for iron, copper and zinc complexation as a multinuclear sulphide clusters in oxic rivers. Nature 406, 879-882.

10 Stumm, W., Morgan, J.J., 1996. Aquatic Chemistry, $3^{\text {rd }}$ Ed. Wiley, New York.

Tipping, E., 1994. WHAM - A chemical equilibrium model and computer code for waters, sediments and soils incorporating a discrete site / electrostatic model of ion-binding by humic substances. Comp. Geosci. 20, 973-1023.

Tipping, E., 1998. Humic Ion-Binding Model VI: an improved description of the interactions of protons and metal ions with humic substances. Aq. Geochem. 4, 3-48.

Tipping, E., Hurley, M.A., 1992. A unifying model of cation binding by humic substances. Geochim. Cosmochim. Acta 56, 3627-3641.

Tipping, E., Marker, A., Butterwick, C., Collett, G., Cranwell, P.A., Ingram, J.K.G., Leach, D.V., Lishman, J.P., Pinder, A., Rigg, E., Simon, B., 1997. Organic carbon in the Humber rivers. Sci. Tot. Environ., 194/195 345-355.

Tipping, E., Woof, C., Hurley, M.A., 1991. Humic substances in acid surface waters; modelling aluminium binding, contribution to ionic charge-balance, and control of $\mathrm{pH}$. Water Res. $25,425-435$. 
Table 1

Parameters for Model V (from Tipping, 1994)

\begin{tabular}{lcl}
\hline parameter & \multicolumn{3}{c}{ comments } \\
\hline$M$ & 1500 & molecular weight \\
$r(\mathrm{~nm})$ & 0.80 & radius \\
$n_{\mathrm{A}}\left(\mathrm{mol} \mathrm{g}^{-1}\right)$ & $4.7 \times 10^{-3}$ & number of type A groups \\
$n_{\mathrm{B}}\left(\mathrm{mol} \mathrm{g}^{-1}\right)$ & $2.4 \times 10^{-3}$ & $=0.5 \times n_{\mathrm{A}}$ \\
$\mathrm{p} K_{\mathrm{A}}$ & 3.3 & median proton dissociation constant for type A groups \\
$\mathrm{p} K_{\mathrm{B}}$ & 9.6 & median proton dissociation constant for type B groups \\
$\Delta \mathrm{p} K_{\mathrm{A}}$ & 3.3 & range factor for $\mathrm{p} K_{\mathrm{A}}$ \\
$\Delta \mathrm{p} K_{\mathrm{B}}$ & 5.5 & range factor for $\mathrm{p} K_{\mathrm{B}}$ \\
$P$ & -103 & electrostatic parameter \\
$f_{p r B}$ & 0.4 & proximity factor for bidentate sites \\
\hline $\mathrm{p} K_{\mathrm{MHA}}$ & & \\
$\mathrm{Mg}$ & 2.2 & \\
$\mathrm{Al}$ & 0.4 & intrinsic equilibrium constants for proton-metal \\
$\mathrm{Ca}$ & 2.2 & exchange at type A sites \\
$\mathrm{Fe}(\mathrm{II})$ & 1.3 & values for type B sites are obtained from the relation: \\
$\mathrm{Fe}(\mathrm{III})$ & -0.2 & p $K_{\mathrm{MB}}=3.96 \mathrm{p} K_{\mathrm{MA}}$ \\
$\mathrm{Cu}$ & 0.8 & \\
$\mathrm{Zn}$ & 1.3 & \\
\hline & & \\
\hline
\end{tabular}


Table 2

Parameters for Model VI (from Tipping, 1998).

\begin{tabular}{|c|c|c|}
\hline parameter & FA & Comments \\
\hline$M$ & 1500 & molecular weight \\
\hline$r(\mathrm{~nm})$ & 0.80 & radius \\
\hline$n_{\mathrm{A}}\left(\mathrm{mol} \mathrm{g}^{-1}\right)$ & $4.8 \times 10^{-3}$ & number of type A groups \\
\hline$n_{\mathrm{B}}\left(\mathrm{mol} \mathrm{g}^{-1}\right)$ & $2.4 \times 10^{-3}$ & $=0.5 \times n_{\mathrm{A}}$ \\
\hline $\mathrm{p} K_{\mathrm{A}}$ & 3.2 & median proton dissociation constant for type A groups \\
\hline $\mathrm{p} K_{\mathrm{B}}$ & 9.4 & median proton dissociation constant for type B groups \\
\hline$\Delta \mathrm{p} K_{\mathrm{A}}$ & 3.3 & range factor for $\mathrm{p} K_{\mathrm{A}}$ \\
\hline$\Delta \mathrm{p} K_{\mathrm{B}}$ & 4.9 & range factor for $\mathrm{p} K_{\mathrm{B}}$ \\
\hline$P$ & -115 & electrostatic parameter \\
\hline$f_{p r B}$ & 0.42 & proximity factor for bidentate sites \\
\hline$f_{p r T}$ & 0.03 & proximity factor for tridentate sites \\
\hline$\Delta L K_{1}$ & 2.8 & range factor for metal binding \\
\hline \multicolumn{3}{|l|}{$\log K_{\mathrm{MA}}$} \\
\hline $\mathrm{Mg}$ & 1.1 & \multirow{7}{*}{$\begin{array}{l}\text { intrinsic equilibrium constants for monodentate } \\
\text { binding at type A sites } \\
\text { values for type B sites are obtained from the relation: } \\
\log K_{\mathrm{MB}}=3.39 \log K_{\mathrm{MA}}-1.15\end{array}$} \\
\hline $\mathrm{Al}$ & 2.5 & \\
\hline $\mathrm{Ca}$ & 1.3 & \\
\hline $\mathrm{Fe}(\mathrm{II})$ & 1.6 & \\
\hline $\mathrm{Fe}(\mathrm{III})$ & 2.4 & \\
\hline $\mathrm{Cu}$ & 2.1 & \\
\hline $\mathrm{Zn}$ & 1.6 & \\
\hline \multicolumn{3}{|l|}{$\Delta L K_{2}$} \\
\hline $\mathrm{Mg}$ & 0.12 & \multirow{7}{*}{$\begin{array}{l}\text { strong binding site term, obtained from the relation: } \\
\qquad \Delta L K_{2}=0.55 \log K_{\mathrm{NH} 3} \\
\text { where } K_{\mathrm{NH} 3} \text { is the equilibrium constant for } \\
\text { complexation with } \mathrm{NH}_{3}\end{array}$} \\
\hline $\mathrm{Al}$ & 0.46 & \\
\hline $\mathrm{Ca}$ & 0.0 & \\
\hline $\mathrm{Fe}(\mathrm{II})$ & 0.81 & \\
\hline $\mathrm{Fe}(\mathrm{III})$ & 2.20 & \\
\hline $\mathrm{Cu}$ & 2.34 & \\
\hline $\mathrm{Zn}$ & 1.28 & \\
\hline
\end{tabular}


Table 3

Details of sampling sites and major solute chemistry of filtered samples.

\begin{tabular}{lcccccccccccc}
\hline & NGR & $\begin{array}{c}\text { DOC } \\
\mathrm{mg} \mathrm{L}^{-1}\end{array}$ & $\mathrm{pH}$ & $\begin{array}{c}\mathrm{Na} \\
\mathrm{mM}\end{array}$ & $\begin{array}{c}\mathrm{Mg} \\
\mathrm{mM}\end{array}$ & $\begin{array}{c}\mathrm{Al} \\
\mu \mathrm{M}\end{array}$ & $\begin{array}{c}\mathrm{Ca} \\
\mathrm{mM}\end{array}$ & $\begin{array}{c}\mathrm{Fe}(\mathrm{III}) \\
\mu \mathrm{M}\end{array}$ & $\begin{array}{c}\mathrm{Cl} \\
\mathrm{mM}\end{array}$ & $\begin{array}{c}\mathrm{NO}_{3} \\
\mathrm{mM}\end{array}$ & $\begin{array}{c}\mathrm{SO}_{4} \\
\mathrm{mM}\end{array}$ & $\begin{array}{c}\mathrm{Alk} \\
\mathrm{meq} \mathrm{L}^{-1}\end{array}$ \\
\hline R. Aire & SE 531 255 & 7.6 & 7.5 & 1.75 & 0.41 & 5.3 & 1.06 & 1.5 & 1.62 & 0.41 & 0.74 & 1.71 \\
R. Calder & SE 409 258 & 5.9 & 7.5 & 1.79 & 0.44 & 3.9 & 0.82 & 2.5 & 1.45 & 0.34 & 0.81 & 1.16 \\
Clatteringshaws Loch & NX 552 765 & 4.6 & 5.6 & 0.19 & 0.03 & 4.9 & 0.04 & 0.3 & 0.23 & 0.01 & 0.03 & 0.01 \\
Coalburn \#1 & NY 692 778 & 18.0 & 4.0 & 0.26 & 0.02 & 6.8 & 0.02 & 7.5 & 0.31 & 0.00 & 0.05 & 0.00 \\
Coalburn \#2 & NY 694 777 & 11.5 & 6.9 & 0.34 & 0.04 & 11.6 & 0.13 & 1.1 & 0.45 & 0.01 & 0.09 & 0.17 \\
R. Derwent & SE 708 364 & 5.6 & 7.9 & 0.66 & 0.35 & 1.7 & 2.50 & 0.6 & 0.98 & 0.36 & 0.81 & 3.19 \\
R. Ouse & SE 591 449 & 4.4 & 8.1 & 0.73 & 0.57 & 1.2 & 2.19 & 0.8 & 1.03 & 0.39 & 0.63 & 3.42 \\
Pool X at Great Dun Fell & NY 714 315 & 15.1 & 4.7 & 0.01 & 0.02 & 5.9 & 0.21 & 6.7 & 0.10 & 0.01 & 0.05 & 0.00 \\
Pool Y at Great Dun Fell & NY 714 315 & 13.3 & 6.8 & 0.12 & 0.02 & 5.2 & 0.20 & 2.8 & 0.10 & 0.01 & 0.04 & 0.33 \\
Roudsea Wood stream & SD 330 828 & 26.7 & 7.2 & 1.72 & 0.19 & 18.9 & 0.64 & 4.2 & 1.59 & 0.01 & 0.11 & 1.54 \\
R. Tees at Bowlees & NY 903 279 & 10.0 & 7.4 & 0.15 & 0.03 & 2.6 & 0.12 & 2.4 & 0.16 & 0.01 & 0.02 & 0.25 \\
R. Tees at Neasham & NZ 327 102 & 6.6 & 7.9 & 0.81 & 0.46 & 2.4 & 1.13 & 2.3 & 0.82 & 0.24 & 0.42 & 2.35 \\
R. Tees at Stockton & NZ 459 191 & 11.5 & 7.7 & 0.78 & 0.43 & 2.2 & 1.02 & 3.0 & 0.70 & 0.29 & 0.46 & 1.85 \\
R. Tees at Whorlton Lido & NZ 106 145 & 9.3 & 7.6 & 0.23 & 0.05 & 2.5 & 0.24 & 3.1 & 0.25 & 0.02 & 0.05 & 0.50 \\
Whitray Beck & SD 683 609 & 20.0 & 4.0 & 0.10 & 0.02 & 2.4 & 0.00 & 4.1 & 0.14 & 0.01 & 0.03 & 0.00 \\
\hline
\end{tabular}


Table 4

Summary of fitting results

\begin{tabular}{|c|c|c|c|c|c|c|c|c|}
\hline & \multicolumn{4}{|c|}{ Model V } & \multicolumn{4}{|c|}{ Model VI } \\
\hline & \multicolumn{2}{|c|}{ without Fe pptn } & \multicolumn{2}{|c|}{ with Fe pptn } & \multicolumn{2}{|c|}{ without Fe pptn } & \multicolumn{2}{|c|}{ with Fe pptn } \\
\hline & FA / DOC & rmsd & FA / DOC & rmsd & FA / DOC & rmsd & FA / DOC & rmsd \\
\hline R. Aire & 1.57 & 0.35 & 1.35 & 0.36 & 1.58 & 0.23 & 1.55 & 0.21 \\
\hline R. Calder & 2.37 & 0.26 & 1.78 & 0.25 & 2.12 & 0.20 & 1.80 & 0.14 \\
\hline Clatteringshaws Loch & 1.46 & 0.10 & 1.42 & 0.09 & 1.01 & 0.17 & 0.96 & 0.19 \\
\hline Coalburn \#1 & 2.71 & 0.31 & 2.67 & 0.31 & 1.77 & 0.11 & 1.31 & 0.16 \\
\hline Coalburn \#2 & 2.32 & 0.35 & 2.01 & 0.28 & 2.14 & 0.26 & 1.02 & 0.28 \\
\hline R. Derwent & 0.18 & 0.24 & 0.00 & 0.24 & 0.81 & 0.17 & 0.80 & 0.16 \\
\hline R. Ouse & 1.18 & 0.20 & 0.87 & 0.20 & 1.35 & 0.14 & 1.30 & 0.13 \\
\hline Pool X at Great Dun Fell & 2.67 & 0.45 & 2.43 & 0.39 & 2.18 & 0.33 & 1.41 & 0.30 \\
\hline Pool Y at Great Dun Fell & 2.38 & 0.42 & 1.74 & 0.43 & 2.19 & 0.35 & 1.09 & 0.22 \\
\hline Roudsea Wood stream & 3.72 & 0.46 & 3.74 & 0.47 & 2.97 & 0.24 & 1.82 & 0.16 \\
\hline R. Tees at Bowlees & 1.99 & 0.26 & 1.90 & 0.31 & 1.81 & 0.08 & 1.18 & 0.14 \\
\hline R. Tees at Neasham & 3.17 & 0.36 & 3.03 & 0.41 & 2.97 & 0.23 & 1.58 & 0.12 \\
\hline R. Tees at Stockton & 2.40 & 0.37 & 2.28 & 0.41 & 2.43 & 0.27 & 1.21 & 0.15 \\
\hline R. Tees at Whorlton Lido & 2.30 & 0.24 & 2.01 & 0.30 & 2.10 & 0.14 & 1.04 & 0.20 \\
\hline Whitray Beck & 2.43 & 0.32 & 2.41 & 0.32 & 2.33 & 0.20 & 1.41 & 0.39 \\
\hline mean & 2.19 & 0.31 & 1.98 & 0.32 & 1.98 & 0.21 & 1.30 & 0.20 \\
\hline standard deviation & 0.85 & - & 0.89 & - & 0.62 & - & 0.30 & - \\
\hline
\end{tabular}




\section{Table 5}

Values of $[\mathrm{FA}]_{\mathrm{opt}} /[\mathrm{DOC}]$ for different data sets. Equilibrium with $\mathrm{Fe}(\mathrm{OH})_{3}$ was assumed in each case.

\begin{tabular}{|c|c|c|}
\hline \multirow[b]{2}{*}{ type of data } & \multicolumn{2}{|c|}{ mean $[\mathrm{FA}]_{\mathrm{opt}} /[\mathrm{DOC}]$} \\
\hline & Model V & Model VI \\
\hline charge-balance data (139 samples) $^{1}$ & 1.12 & 1.22 \\
\hline Al speciation (108 samples) ${ }^{1}$ & 1.47 & 1.56 \\
\hline 11 base titrations of $\mathrm{Cu}$-amended natural waters ${ }^{2}$ & 1.31 & 1.45 \\
\hline $15 \mathrm{Cu}$ titrations of $\mathrm{pH}$-adjusted natural waters ${ }^{3}$ & 1.98 & 1.30 \\
\hline mean & 1.47 & 1.38 \\
\hline standard deviation & 0.32 & 0.13 \\
\hline
\end{tabular}

${ }^{1}$ Data sets assembled by Tipping et al. (1991)

${ }^{2}$ Data of Dwane and Tipping (1998)

${ }^{3}$ Present work 
Table 6

The influence of the choice of equilibrium constant $(\log K)$ for the reaction $\mathrm{Cu}^{2+}+\mathrm{H}^{+}+\mathrm{CO}_{3}{ }^{2-}$ $=\mathrm{CuHCO}_{3}{ }^{+}$on copper speciation calculated with WHAM / Model VI. The results are expressed in terms of $\mathrm{p}\left[\mathrm{Cu}^{2+}\right]\left(\left[\mathrm{Cu}^{2+}\right]\right.$ in $\left.\mathrm{mol} \mathrm{L}^{-1}\right)$, and refer to a total $\mathrm{Cu}$ concentration of 1 $\mu \mathrm{M}$. The concentration of FA was estimated from [DOC] by multiplying by 1.3 (see text).

\begin{tabular}{|c|c|c|c|c|c|c|}
\hline \multirow[b]{2}{*}{$\mathrm{pH}$} & \multirow[b]{2}{*}{$\mathrm{pCO}_{2}$} & \multirow[b]{2}{*}{$\log K$} & \multicolumn{4}{|c|}{ [DOC] $\mathrm{mg} \mathrm{L}^{-1}$} \\
\hline & & & 0 & 1 & 5 & 10 \\
\hline \multirow{4}{*}{5.5} & \multirow{2}{*}{0.00035} & 12.13 & 6.00 & 6.18 & 7.00 & 7.68 \\
\hline & & 14.62 & 6.01 & 6.19 & 7.01 & 7.68 \\
\hline & \multirow{2}{*}{0.001} & 12.13 & 6.00 & 6.18 & 7.00 & 7.68 \\
\hline & & 14.62 & 6.03 & 6.20 & 7.01 & 7.69 \\
\hline \multirow{4}{*}{7.0} & \multirow{2}{*}{0.00035} & 12.13 & 6.06 & 6.59 & 8.36 & 9.11 \\
\hline & & 14.62 & 6.26 & 6.71 & 8.36 & 9.11 \\
\hline & \multirow{2}{*}{0.001} & 12.13 & 6.12 & 6.62 & 8.36 & 9.11 \\
\hline & & 14.62 & 6.50 & 6.88 & 8.36 & 9.11 \\
\hline \multirow{4}{*}{8.5} & \multirow{2}{*}{0.00035} & 12.13 & 7.93 & 8.26 & 10.00 & 10.90 \\
\hline & & 14.62 & 8.03 & 8.33 & 10.00 & 10.90 \\
\hline & \multirow{2}{*}{0.001} & 12.13 & 8.40 & 8.62 & 9.99 & 10.86 \\
\hline & & 14.62 & 8.49 & 8.70 & 10.00 & 10.86 \\
\hline
\end{tabular}


Fig. 1 Copper titration results for the sample from the River Tees at Stockton. The results refer to $\mathrm{pH} 6, I=0.1 \mathrm{M}$ (closed circles), $\mathrm{pH} 6$, natural ionic strength (open circles) and $\mathrm{pH} 7$, natural ionic strength (closed squares). The dotted lines are model fits assuming all Fe(III) to be in solution, the full lines are fits assuming the activity of $\mathrm{Fe}^{3+}$ to be controlled by $\mathrm{Fe}(\mathrm{OH})_{3}$.

Fig. 2 Copper titration data fitted with Model VI with precipitation of $\mathrm{Fe}(\mathrm{OH})_{3}$. The symbols have the same meaning as those in Fig. 1.

Fig. 3 Comparisons of predicted and observed $\left[\mathrm{Cu}^{2+}\right]$ at $[\mathrm{Cu}]_{\text {tot }}=1 \mu \mathrm{M}$. The observed values are from all the titrations carried out on the 15 samples studied in the present work. The calculated values were obtained by applying Models V and VI, assuming equilibrium with $\mathrm{Fe}(\mathrm{OH})_{3}$, and using the mean $[\mathrm{FA}]_{\mathrm{opt}} /[\mathrm{DOC}]$ ratios given in Table 4 . The dotted lines include $95 \%$ of the calculated values. 

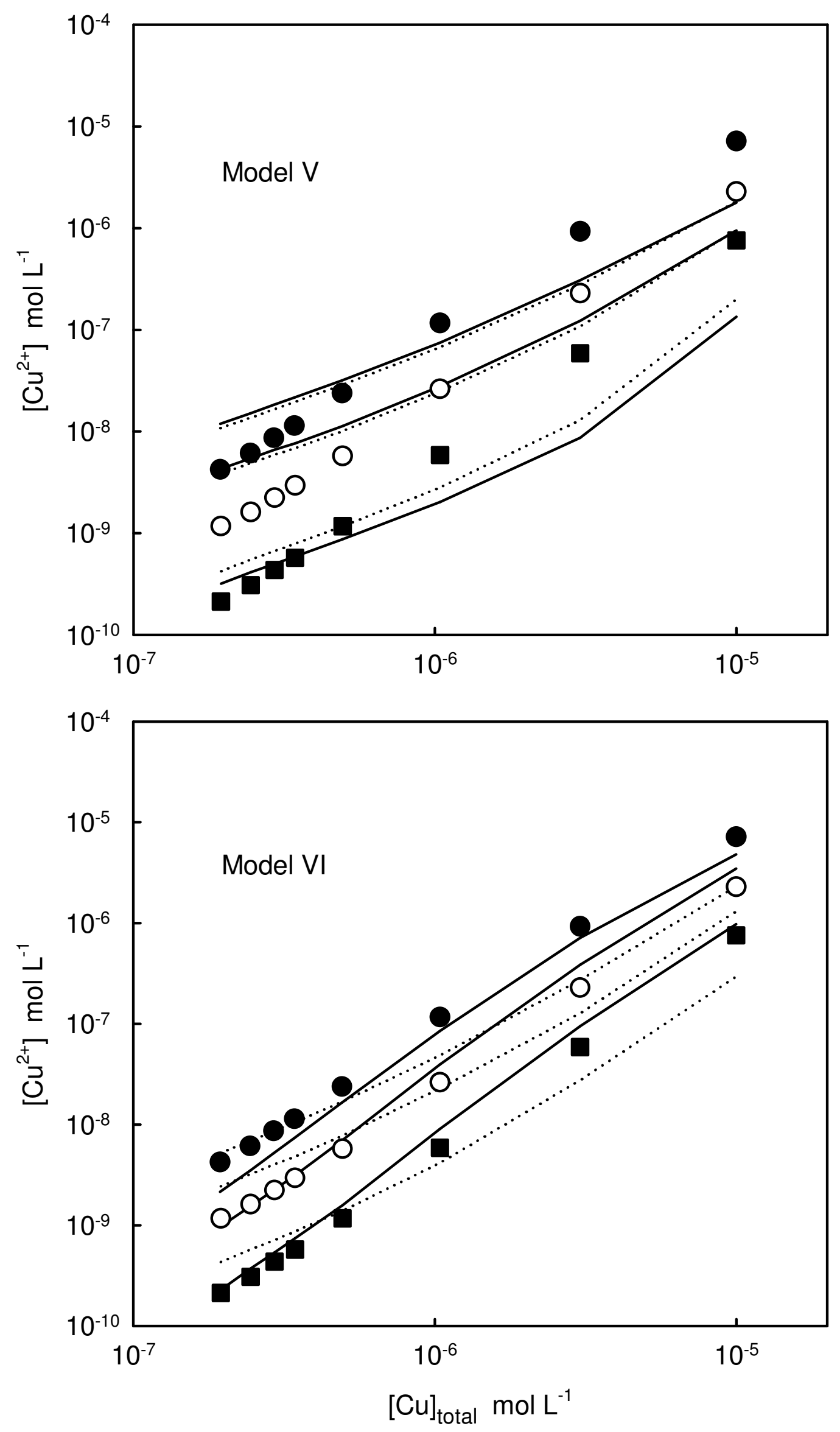

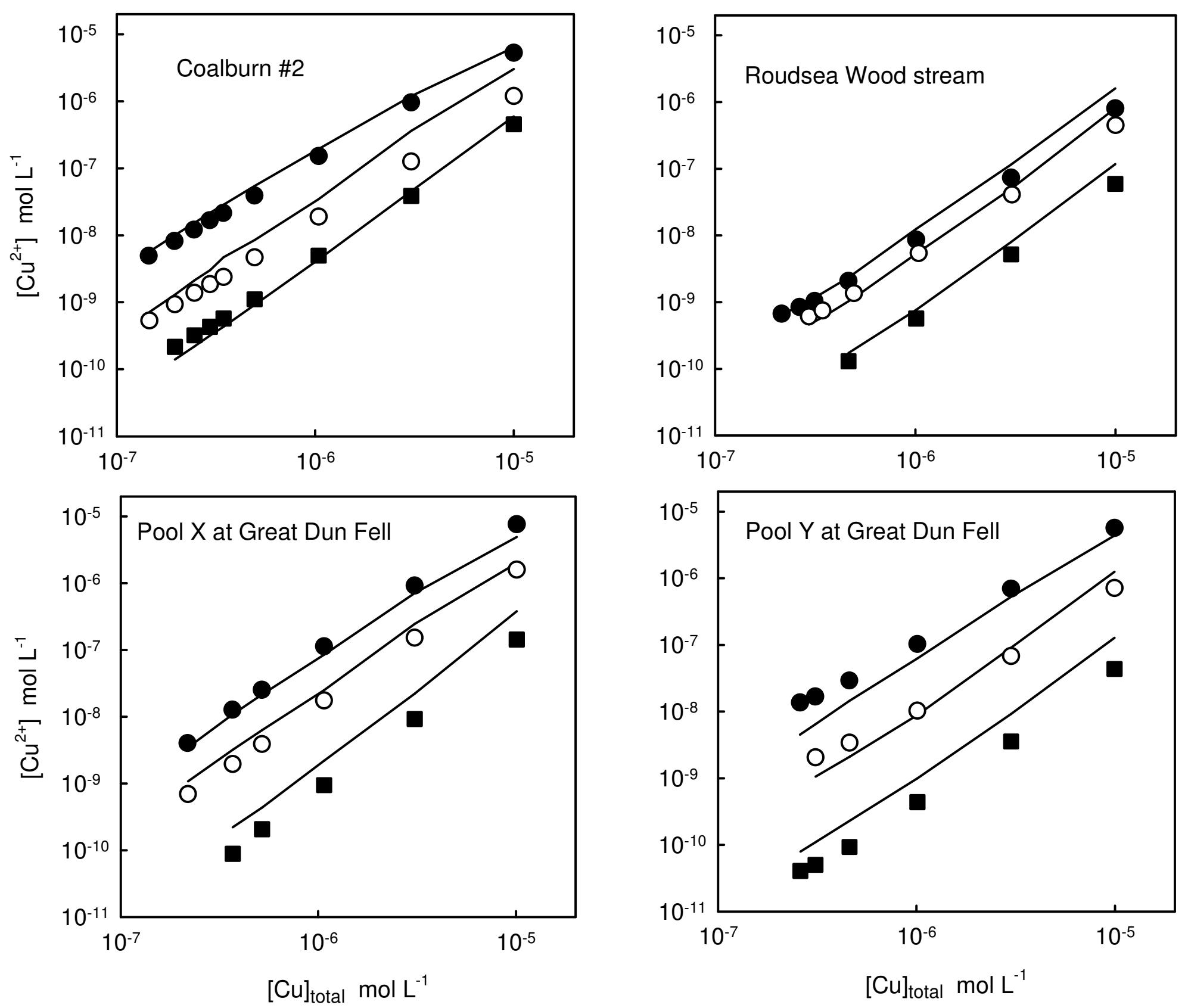

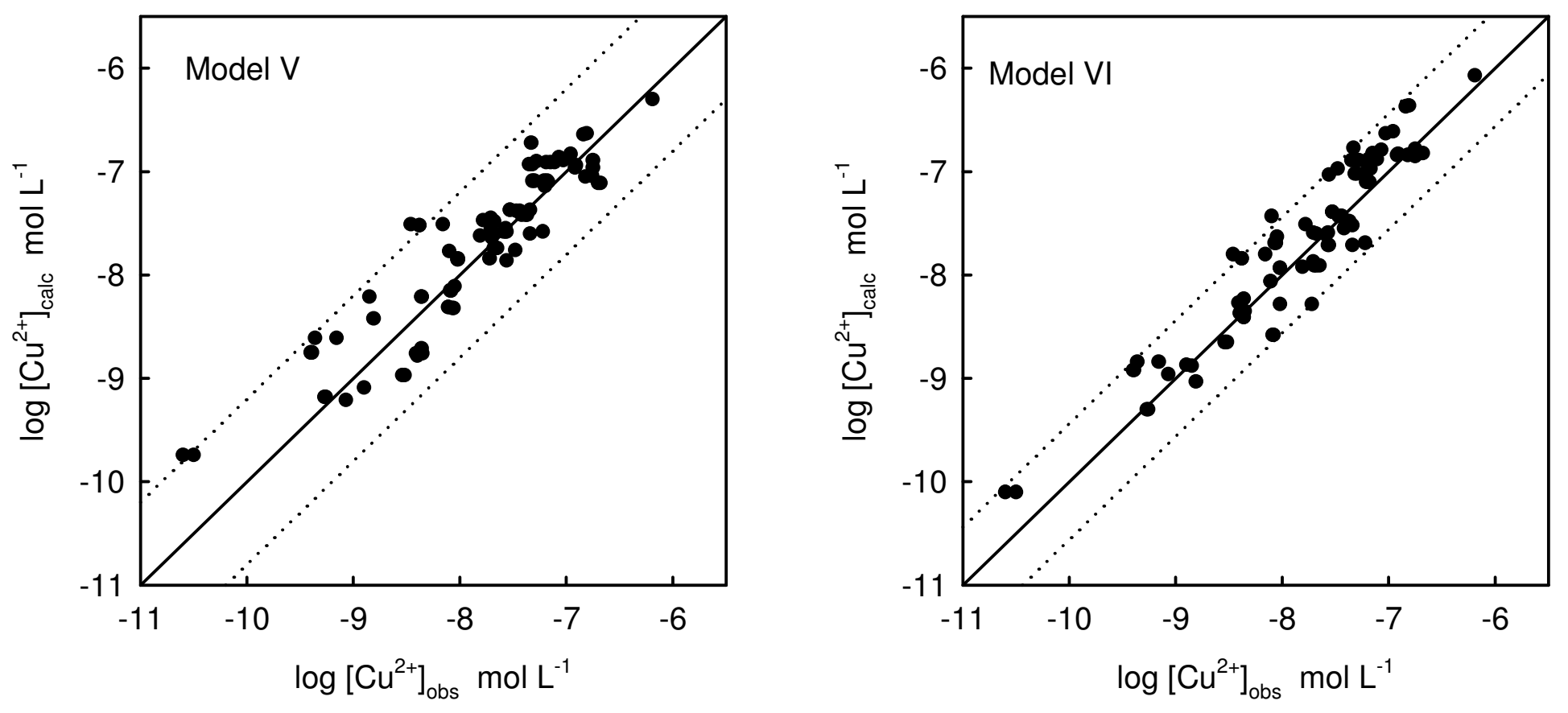